\title{
Erratum to: Histological changes in the liver of reared spotted scat (Scatophagus argus L.) after exposure to mercury
}

\author{
Hassan Morovvati • Yadollah Nikpour • \\ Hossein Zolgharnein • Mohammadtaghi Ronagh • \\ Rahim Abdi • Aram Roshan
}

Published online: 7 July 2011

(C) Springer-Verlag London Limited 2011

\section{Erratum to: Comp Clin Pathol DOI 10.1007/s00580-010-1168-1}

Due to an oversight on the part of the authors, an incorrect name of one of the co-authors was published in the manuscript entitled "Histological changes in the liver of reared spotted scat(Scatophagus argus L.) after exposure to mercury".

The correct name of the author is Hossein Zolgharnein.

The online version of the original article can be found at http://dx.doi. org/10.1007/s00580-010-1168-1.

H. Morovvati $(\bowtie)$

Department of Histology, Faculty of Veterinary Medicine,

Shahid Chamran University of Ahvaz,

P.O. Box 61355-145, Ahvaz, Iran

e-mail: hmorovvati@scu.ac.ir

Y. Nikpour · H. Zolgharnein · M. Ronagh $\cdot$ R. Abdi $\cdot$ A. Roshan Khoramshahr Marine Science and Technology University,

P.O. Box 669, Khoramshar, Iran 